\title{
Formation and characterization of FeLV ISCOMs
}

\begin{abstract}
L. Åkerblom* ${ }^{*}$ K. Strömstedt ${ }^{\dagger}$, S. Hoglund ${ }^{\ddagger}$, A. Osterhaus ${ }^{\S}$ and B. Morein ${ }^{* \dagger}$
Immunostimulating complexes (ISCOMs) have been prepared from feline leukaemia virus (FeLV) envelope proteins. The ISCOMs were characterized biochemically in SDS-polyacrylamide gel electrophoresis showing the presence of proteins of estimated molecular weights of 15000,27000 and 70000 . Immunoblotting showed that both the transmembrane protein p15E and the external glycoprotein gp70 (making up the gp85 protein) were present in the ISCOM. Furthermore, a degradation product of gp70 with an estimated molecular weight of 32000 was identified in the immunoblot. The FeLV ISCOM was shown by electron microscopy to have the characteristic cage-like structure of an ISCOM with a mean diameter of $37 \mathrm{~nm}$. About $10 \%$ of the total amount of $\mathrm{gp} 70$ in the culture fluid was recovered in the ISCOMs. The largest loss was encountered during the sedimentation of the virus. In a preliminary immunization experiment in mice the FeL V ISCOMs elicited after a booster gave a clear-cut immune response against gp70.
\end{abstract}

Keywords: ISCOM; FeLV; vaccine

\section{Introduction}

Feline leukaemia virus (FeLV) belongs to the Retroviridae family, subfamily Oncovirinae. It has a worldwide distribution and may cause leukaemia in cats, but more often it causes an immunodeficiency syndrome. It is considered that the protective antigen is the glycosylated envelope protein with a molecular weight of $70000(\mathrm{gp} 70)^{1}$. Like most other retroviruses, the envelope of FeLV is first formed as a precursor protein (gp85). This is cleaved with a trypsin or a trypsin-like cellular enzyme of gp70 and p15E during intracellular transport to the plasma membrane before budding out with the virus particle. Gp70 being the peripheral part of the envelope protein, is to a great extent detached from the transmembrane protein p15E and the virus particle, and is found in the cell culture medium; p15E, however, remains integrated in the virus envelope.

Recently it was shown in an immunization experiment in cats by Osterhaus et al..$^{2,3}$ that gp 70 integrated into an immunostimulating complex (ISCOM) ${ }^{4}$ could induce protection to challenge infection in cats. The immunization experiment was extended to a larger experiment including 140 cats $^{3,5}$. In this experiment about $85 \%$ of the ISCOMimmunized cats developed virus-neutralizing antibodies, available vaccine developed neutralizing antibodies. It had earlier been shown by Essex et al. ${ }^{6}$ and later by others ${ }^{7,8}$ that cats with neutralizing antibodies to FeLV do not develop disease, i.e. they have protective immunity to

"The Swedish University of Agricultural Sciences, Faculty of Veterinary Medicine, Department of Veterinary Microbiology, Section of Virology, Biomedical Center, Box 585, S-751 23 Uppsala, Sweden. The National Veterinary Institute, Department of Virology, Biomedical Center, Box 585 , S-751 23 Uppsala, Sweden, ${ }^{+}$Uppsala University, Department of Biochemistry, Biomedical Center, Box 576, S-751 23 Uppsala, Sweden. ${ }^{9}$ National Institute of Health, Postbus 1, NL-3720 Bilthoven, The Netherlands. (Received 26 August 1988)

0264-410X/89/020142-05\$03.00

(C) 1989 Butterworth \& Co. (Publishers) Lto

142 Vaccine, Vol. 7, April 1989
FeLV. It has also been shown with a monoclonal antibody that gp 70 contains at least one neutralizing epitope ${ }^{1}$ and that this epitope is conserved in the three known serotypes.

In the present work we describe the preparation of ISCOMs containing FeLV gp 70, and we characterize them as regards their morphology, their content of gp70, p15E and a breakdown product of gp70 migrating as a 32000 molecular weight protein in an SDS-polyacrylamide gel electrophoresis. A preliminary immunization study in mice is also documented and the prospects of a vaccine are discussed.

\section{Materials and methods \\ Materials}

The detergent MEGA-10 (n-decanoyl-methyl glucamine $)^{9}$ was synthesized according to the method of Hildreth ${ }^{10}$. MEGA-10 was used as a $20 \%$ stock solution in water. Quil A 'Spikoside' was from Iscotec AB (Luleå, Sweden). Quil A was used as a $10 \%$ stock solution in water. The crosslinker DTNP (dithiobis- $m$-nitropyridine) was used as a $0.2 \%$ stock solution in $\mathrm{DMSO}^{11}$.

Antisera. A mouse monoclonal antibody (mAb) against $\mathrm{gp} 70^{2}$ was used in the detection and purification of gp70. A hyperimmune antiserum against $\mathrm{pl}$ 15E from Raucher murine leukaemia virus was a generous gift from Dr Oswald Jarrett, Glasgow, Scotland.

Cells and virus. The cat T-lymphoma cell line $\mathrm{F} 422^{12}$ was used for the propagation of FeLV. Cells were grown in RPMI 1640 (The National Veterinary Institute, Sweden) supplemented with $10 \%$ fetal calf serum, $100 \mathrm{IU}$ penicillin and $100 \mu \mathrm{g}$ streptomycin $\mathrm{ml}^{-1}$. Cultures up to 5 litres were grown in Roller bottles or in Spinner culture flasks. Larger volumes of cultures were run in a fermenter equipment from Chemoferm AB, Sweden. Harvested cell culture fluid was freed from cells and cell debris by low-speed 
centrifugation at $4000 \mathrm{rev} \mathrm{min}^{-1}$ for $30 \mathrm{~min}$ in a Sorvall rotor GS3. The supernatant was collected and concentrated 10-15 times by ultrafiltration through a pellicon filter (Millipore PTMK 00005) with an exclusion limit of 300000 . From the concentrate the virus was sedimented at 20000 rev min for $^{-1} \mathrm{~h}$ at $10^{\circ} \mathrm{C}$ in a Kontron TFA 20 rotor. The virus pellet was suspended in $10 \mathrm{ml} 0.5 \mathrm{M}$ Tris, $0.15 \mathrm{M} \mathrm{NaCl} \mathrm{pH} 7.5$ (TN) and layered over a $30 \%$ sucrose cushion. The virus was centrifuged at $28000 \mathrm{rev} \mathrm{min}^{-1}$ for $2 \mathrm{~h}$ at $10^{\circ} \mathrm{C}$ in a Kontron TST 28.38 rotor. This step was avoided for some virus batches in an effort to minimize the loss of $\mathrm{gp} 70$, due to shearing forces during centrifugation. From the stock solution the crosslinker (DTNP) was added to a concentration of $0.02 \%$ and incubated for $30 \mathrm{~min}$ at room temperature to stabilize the binding of gp70 to the membrane anchoring part, p15E.

\section{Methods}

Labelling of virus glycoproteins. To dividing F422 cells were added $400 \mu \mathrm{Ci}$ glucosamine (TRK.398, Amersham), in $250 \mathrm{ml}$ RPMI 1640 medium free from glucose and supplemented with $10 \%$ fetal calf serum, over $24 \mathrm{~h}$.

Formation of ISCOM. This was essentially performed as described before ${ }^{4}$. To a virus sample of approximately $200 \mathrm{mg}$ in $8 \mathrm{ml} \mathrm{TN}, 0.9 \mathrm{ml}$ of the stock solution of MEGA was added to a final concentration of $2 \%$ and left for $2 \mathrm{~h}$ at room temperature. The solubilized virus was layered on top of $10 \%$ sucrose in $\mathrm{TN}$ in a volume of $2 \mathrm{ml}$ containing MEGA at a concentration of $0.2 \%$, with a layer of $30 \%$ sucrose in TN underneath. The solubilized virus was centrifuged at $30000 \mathrm{rev}$ permin for $2 \mathrm{~h}$ at $20^{\circ} \mathrm{C}$ in a TST.41.14 rotor. The top fraction consisting of the sample volume plus the $10 \%$ sucrose layer was collected and Quil A was added to a concentration of $0.1 \%$. The mixture was extensively dialysed against TN.

SDS-polyacrylamide gel electrophoresis. This was done in a $12 \%$ gel according to Laemmli ${ }^{13}$.

Western blots. These were done according to Towbin et al. ${ }^{14}$ using nitrocellulose filter paper from Schleicher \& Schüll, FRG.

Purification of gp70. FeLV gp70 was purified by an immunosorbent technique from culture fluid media or from infected cells. A monoclonal antibody recognizing a neutralizing epitope on $\mathrm{gp} 70^{2}$ was coupled to $\mathrm{CNBr}$ activated sepharose (Pharmacia, Sweden) following the manufacturer's description. $\mathrm{Gp} 70$ was eluted with $0.1 \mathrm{M}$ Tris $\mathrm{pH}$ 11.0. Fractions containing protein were adjusted to $\mathrm{pH} 8.0$ with $1 \mathrm{M} \mathrm{HCl}$.

Quantification of gp70. A quantitative dot-immunoblot using affinity-purified gp70 and a monoclonal antigp70 antibody were used to determine the amount of gp70 in virus and ISCOMs. In the dot-immunoblot analysis a nitrocellulose filter holder from Bio-Rad (USA) was used.

Fluorography. To analyse the glycoprotein content of a virus preparation, virus labelled with tritiated glucosamine was electrophoresed in SDS-PAGE gels and soaked in scintillator fluid (Amplify, Amersham, England). The gel was dried. The radioactivity pattern was analysed by fluorography using Kodak X-AR 5 film.
Protein determination. This was performed by the method of Bradford ${ }^{15}$ using bovine serum albumin as standard.

$\boldsymbol{E L I S A}$. The ELISA ${ }^{16}$ was performed in microtitre Immunoplates I (Nunc, Roskilde, Denmark). The plates were coated overnight at $4^{\circ} \mathrm{C}$ with either highly purified gp70 at a concentration of $1 \mu \mathrm{g} \mathrm{m}^{-1}$ or with FeLV ISCOMs at a concentration of $3 \mu \mathrm{g} \mathrm{ml}^{-1}$ in $50 \mathrm{~mm}$ carbonate buffer $\mathrm{pH}$ 9.6. All washings were made with phosphate-buffered saline (150 mM, pH 7.5) containing $0.2 \%$ Tween-20 (PBS-Tween). The plates were blocked with $5 \%$ dried milk in PBS-Tween for $1 \mathrm{~h}$ at $37^{\circ} \mathrm{C}$. Antisera were diluted in PBS-Tween and incubated for $1 \mathrm{~h}$ at $37^{\circ} \mathrm{C}$. Horseradish peroxidase conjugated rabbit anti-mouse and swine anti-rabbit (Dakopatts, Copenhagen, Denmark) were diluted $1: 1000$ in PBS-Tween and incubated for $1 \mathrm{~h}$ at $37^{\circ} \mathrm{C}$. The enzyme reactions were visualized with tetramethylbenzidine $\left(0.19 \mathrm{mg} \mathrm{ml}^{-1}\right)$ (Sigma, USA) and $\mathrm{H}_{2} \mathrm{O}_{2}$ $(0.006 \%)$ in $0.1 \mathrm{M}$ acetate buffer pH 6.0 and absorbance was measured at $450 \mathrm{~nm}$ with a Titertek Multiscan spectrophotometer (Flow Laboratories, Irvine, Scotland).

Electron-microscopic analysis. Samples of ISCOMs were applied to hydrophilic, carbon-coated grids. For dialysis the specimens were placed upside down on microdroplets of $0.1 \mathrm{M}$ phosphate buffer, $\mathrm{pH} 7.0$ before negative staining with ammonium molybdate, $\mathrm{pH}$ 7.0. The specimens were studied in a Philips 300 electron microscope at $60 \mathrm{kV}$ accelerating voltage to improve the contrast effect. Photographs were taken in through focal series with minimal beam exposure.

\section{Results}

\section{Formation and characterization of FeLV ISCOMs}

FeLV originating from the cat T-lymphoma cell line F422 was concentrated and enriched by centrifugation. The virus material was solubilized with the detergent MEGA and the envelope proteins were integrated into ISCOMs by the dialysis method.

Recovery. The amount of the envelope protein $\mathrm{gp} 70$ was estimated at different steps of purification by a quantitative dot-immunoblot method using a monoclonal antigp70 antibody with highly purified gp70 as a standard. The purification steps include: (1) concentration by ultrafiltration where little loss occurred; (2) sedimentation of virus by two centrifugations where most of the gp 70 was lost, approximately $70 \%$; (3) the preparation of ISCOMs with a centrifugation and a dialysis procedure where an additional $20 \%$ of the gp 70 was lost. The remainder is $<10 \%$ of the amount of gp 70 of the starting material. The detailed results are given in Table 1.

Table 1 Relative recovery of $\mathrm{gp} 70$ at different steps of virus purification and ISCOM preparation as measured by a quantitative dot-immunoblot method

\begin{tabular}{lcc}
\hline & $\begin{array}{l}\text { Percentage recovery } \\
\text { of gp70 from }\end{array}$ \\
\cline { 2 - 3 } $\begin{array}{l}\text { Different steps in the purification of virus } \\
\text { and formation of ISCOMs }\end{array}$ & $\begin{array}{l}\text { Original } \\
\text { material }\end{array}$ & Preceding \\
step
\end{tabular}




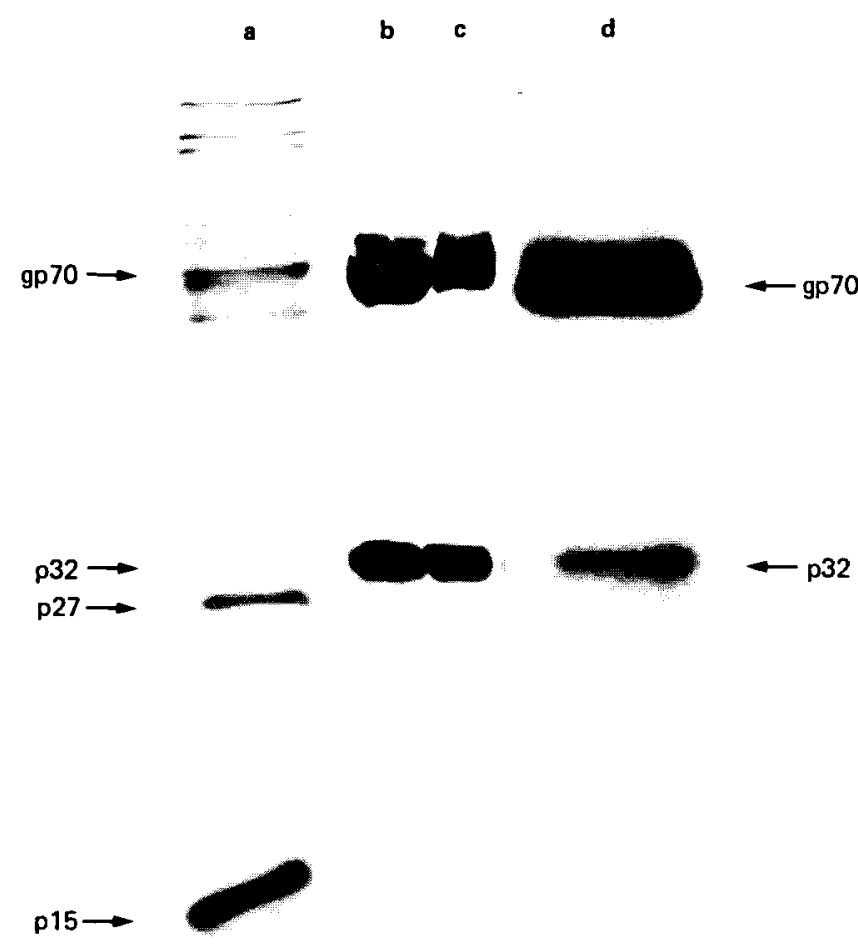

$p 15 \rightarrow$
Electron-microscopic evaluation of FeLV ISCOMs. A relatively homogeneous population of ISCOM particles was observed by electron microscopy (Figure 4), demonstrating a characteristic cage-like structure. The diameter of the projections of ISCOM varied from 30 to $45 \mathrm{~nm}$ with a mean diameter of $37 \mathrm{~nm}$. When ISCOM par-

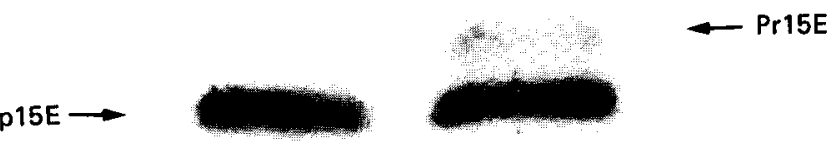

Figure 1 Analysis of FeLV and FeLV ISCOMs in SDS-polyacrylamide ge electrophoresis and in Western blot for the presence of the envelope protein gp70. (a) SDS-PAGE gel analysis of FeLV ISCOMs; (b) Western blot analysis of virus lysate using an anti-gp70 mAb; (c) Western blot analysis of FeLV ISCOMs using an anti-gp70 mAb; (d) autoradiogram of affinitypurified $\left[{ }^{3} \mathrm{H}\right]$ glucosamine-labelled gp70 separated in an SDS-PAGE gel

The protein pattern of the FeLV ISCOM. This was analysed in an SDS-PAGE and Western blot as described in Materials and Methods (Figure 1). Several protein bands are visible. The two most prominent bands in the ISCOM preparation migrated as proteins with molecular weights of 15000 and 27000 respectively. They probably represent the gag-coded proteins p15 and p27. Besides detecting a protein in the $70 \mathrm{kDa}$ region, the monoclonal antibody to gp 70 also identified a band in the $32 \mathrm{kDa}$ region of the PAGE of the virus as well as of the ISCOM (Figure $1 b, c$ ). The 70 and $32 \mathrm{kDa}$ bands were also identified by fluorography with immunosorbent-purified $\left[{ }^{3} \mathrm{H}\right]$ glucosamine-labelled gp 70 separated in SDS-PAGE (Figure Id).

By Western blot analysis the transmembrane protein p15E was detected in virus and ISCOMs using rabbit hyperimmune antiserum. Two bands were detected in the virus lysate, but in the ISCOM preparation only the $15 \mathrm{k}$ band was visible (Figure 2).

ELISA analysis of FeLV ISCOMs. The FeLV ISCOMs were tested as antigen in ELISA against a monoclonal antibody to gp 70 and against a rabbit anti-serum to p15E (Figure 3). The reading was plotted against the recriprocal antibody dilutions expressed as a natural logarithm. The behaviour and the slope of the curves for the two antisera are similar, indicating equal amounts of p15E and gp70 in the ISCOM preparation.

Figure 2 Western blot analysis of FeLV ISCOMs (a) and FeLV lysate (b) using a rabbit hyperimmune anti-p15E antiserum

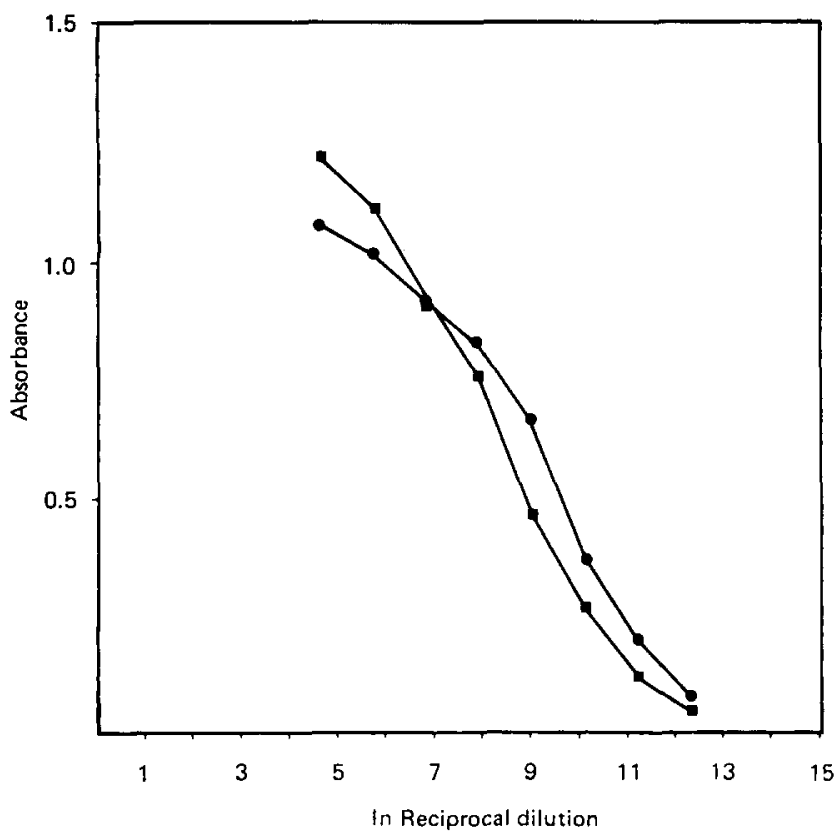

Figure 3 Analysis of FeLV ISCOMs in ELISA for the presence of gp70 and p15E. The ELISA plates were coated with FeLV ISCOMs and incubated with different dilutions of the anti-gp70 $\mathrm{mAb}(\bullet)$ and the anti-p15E antiserum ( 1 ) (see Materials and methods) 


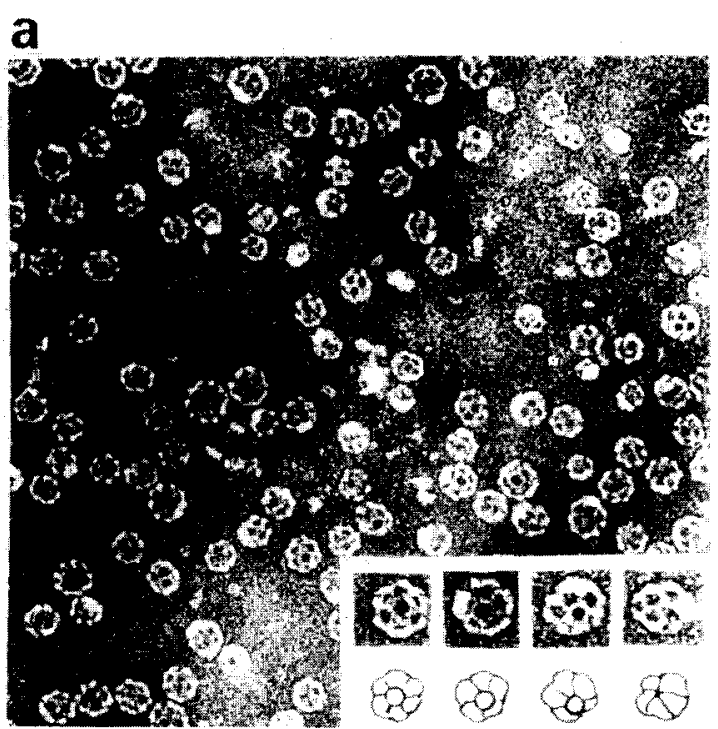

b

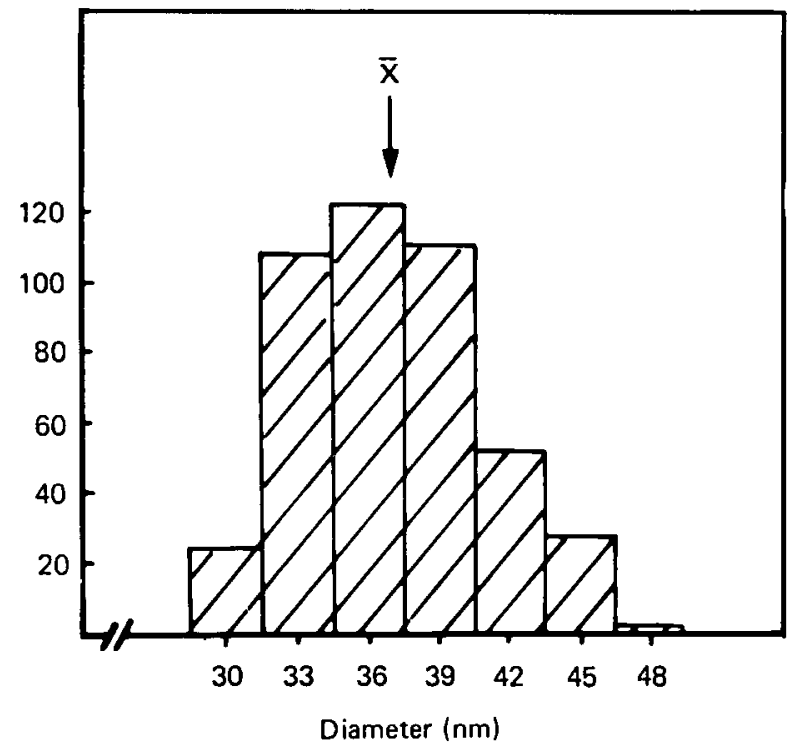

Figure 4 Electron microscopy of FeLV ISCOMs. (a) Electron micrograph of ISCOM particles, negatively stained by ammonium molybdate, showing projections of cage-like structures $(\times 125000)$. A central, ring-like subunit of the shell of the ISCOM is shown in different projections in the insert, also demonstrated by the drawings. (b) Histogram of the distribution of the diameter of the projection of negatively stained ISCOM particles with an arithmetic mean value of $37 \mathrm{~nm}$

ticles in different tilt angles were analysed they appeared slightly flattened.

Immunization of mice with FeLV ISCOMs. In a preliminary study two sets of five mice were immunized with FeLV ISCOMs with a total protein dose of 0.3 and $3.0 \mu \mathrm{g}$ respectively. The gp70 content of FeLV ISCOMs in this study was estimated to be $5 \%$ of the total protein content corresponding to a dose of 15 and $150 \mathrm{ng}$ of gp70 respectively.

The serum titres were tested against highly purified gp70 in an ELISA. Low but clear-cut serum titres were detected against gp 70 by this assay. The end dilution titres for the two sets of mice after the first and second immunization were as shown in Figure 5.

\section{Discussion}

Like most retroviruses, the peripheral and glycosylated part of the envelope protein gp 70 of FeLV detaches from the anchoring and transmembrane part $-\mathrm{p} 15 \mathrm{E}$. This fact makes it difficult to isolate and to assemble gp70 to micelles, or to ISCOMs, by hydrophobic interactions to enhance its immunogenicity. The necessity of presenting immunogens in defined physical forms with multimeric presentation of the antigen has been reviewed ${ }^{17}$. The most immunogenic of such complexes seems to be the ISCOM ${ }^{18}$. However, an experimental ISCOM vaccine based on $\mathrm{gp} 70$ has already been shown to protect cats against challenge ${ }^{2}$. This vaccine was essentially prepared as described here, with a high amount of starting material and a low yield.

From Table 1 it is evident that the major loss of $\mathrm{gp} 70$ antigen occurs during the centrifugation steps. The monomeric, highly water-soluble gp 70 , with a comparatively low sedimentation coefficient, is readily separated from the faster-sedimenting virus particle. The addition of DTNP, which is used with the intention of stabilizing disulphide linkage between $\mathrm{p} 15 \mathrm{E}$ and $\mathrm{gp} 70^{11}$, did not prevent a major loss of remaining gp 70. In the procedure used here, DTNP had to be added after the first centrifugation to avoid precipitation. It might be worth testing whether DTNP is more useful if the first centrifugation is replaced with another concentration and purification step. The final recovery of gp70 (in our procedure for making ISCOM) was $\leqslant 10 \%$ and virtually all losses occurred during the virus-isolation procedures, as found with the preparation of ISCOMs with gp51 of bovine leukaemia virus $^{19}$. Therefore, alternative methods for making immunogenic complexes based on hydrophobic interactions such as protein micelles or virosomes would not solve this

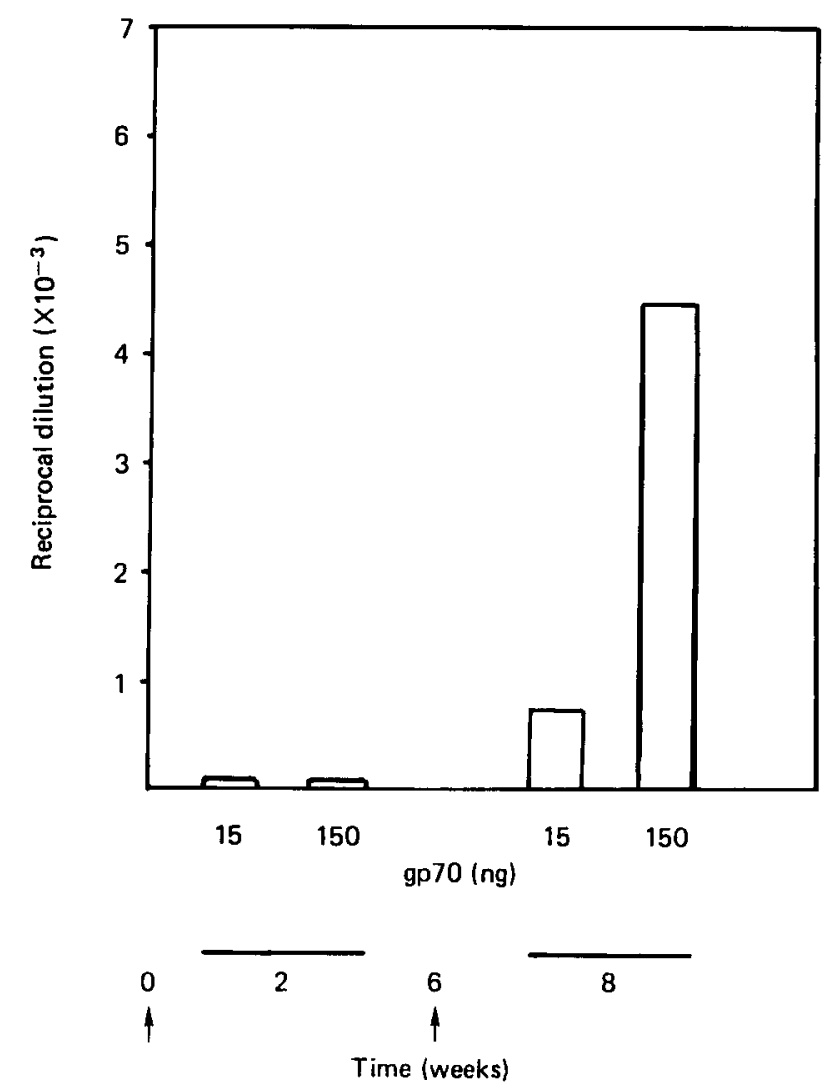

Figure 5 Serum antibody titres to gp70 in mice immunized with FeLV ISCOMs as measured by ELISA. Arrows show first and second vaccination 
problem. An efficient way to preclude described losses of gp70 is by use of an animal cell producing the complete envelope protein gp85, e.g. after transfection with an animal cell vector cloned with the env gene where the cleavage region of gp70 is deleted. The product of such a construct of the env gene for gp 160 of HIV was efficiently integrated into ISCOMs.

The ISCOM preparation was analysed in PAGE and Western blot. In the PAGE the most prominent virus bands of virus proteins seem to be p15 and p27, while gp 70 and $\mathrm{p} 15 \mathrm{E}$ are less prominent. In the Western blot, on the other hand, gp70 and pl5E respectively are readily recognized with a monoclonal antibody (gp 70$)$, which is recognizing a neutralizing epitope, and a polyclonal serum (p15E). This antibody (anti-gp70) is, therefore, potentially useful as a quality control tool for this experimental vaccine, as described by Merza et al. ${ }^{19}$, who used neutralizing monoclonal antibodies to control an experimental BLV vaccine. The ISCOM preparation described here reacted also in ELISA with this antibody under a less denaturing condition than the Western blot. In the Western blot this antibody, as well as detecting a band migrating as a $70 \mathrm{kDa}$ protein in the SDS-PAGE, also detected a $32 \mathrm{kDa}$ band. This band was present both in the virus particle preparation and the ISCOM. It is probably a split or degradation product of $g \mathrm{p} 70^{20}$ and less is found in freshly prepared virus or ISCOMs than in older preparations. The other split product with an expected molecular weight of $30000-40000$ has not yet been identified. FeLV ISCOMs comprising different proteins were analysed by electron microscopy by a size distribution of the ISCOM particles. Although somewhat flattened, as judged by different tilt projections in electron microscopy (Figure 4a), a variation in diameter (Figure $4 b)$ may refiect a variation in volumes of the ISCOMs. The proteins in the shell of the cage-like ISCOM were efficiently exposed.

Another interesting observation is that the antibody recognizing $\mathrm{p} 15 \mathrm{E}$ recognized two bands in the virus preparation but not in the ISCOM. The additional band has a slightly higher molecular weight in SDS-PAGE and may represent a precursor protein to $\mathrm{p} 15 \mathrm{E}$, as described for murine leukaemia virus ${ }^{21}$. The rabbit anti-Raucher $\mathrm{p} 15 \mathrm{E}$ coprecipitates two proteins with estimated molecular weights of $12 \mathrm{kD}$ and $15 \mathrm{kD}$. The presence of $\mathrm{p} 15 \mathrm{E}$ was necessary for the coprecipitation with gp 70. Virus preparations from $\mathrm{F} 422$ cells lacked p15E, but contained p12E, and failed to coprecipitate gp $70^{22}$. This might explain the low yield of gp 70 recovered from virus produced by F422 cells.

In a dilution experiment with the monoclonal antibody to gp70 and the antiserum to $\mathrm{p} 15 \mathrm{E}$, similar titration curves were obtained, which should indicate that the number of the two molecules were of the same magnitude. We would have expected the number of p15E molecules to exceed that of gp 70 due to the great loss of gp 70 .

The FeLV ISCOMs produced as described here, readily induced antibody to highly purified gp 70 in mice (Figure 4) after two doses containing as little as $15 \mathrm{ng}$ gp70. The specificity of the antibody was confirmed in Western blot. It would, of course, be interesting to test in the natural host, i.e. the cat. Such experiments are presented in a subsequent paper ${ }^{5}$.

\section{Acknowledgements}

This work was supported by grants from the Swedish Board for Technical Development (87-01807P) and from the Swedish Cancer Society (2201-B88-03XB).

\section{References}

1 Grant, C.K., Ernisse, B.J., Jarrett, O. and Jones, F.R. Feline leukemia virus envelope gp70 of subgroups $B$ and $C$ defined by monoclonal antibodies with cytotoxic and neutralizing functions. J. Immunol. 1983, 131, 3042

2 Osterhaus, A., Weijer, K., UytdeHaag, F., Jarrett, O., Sundquist, B. and Morein, $B$. Induction of protective immune response in cats by vaccination with feline leukemia virus ISCOM. J. Immunol. 1985, 135, 591

3 Osterhaus, A., Weijer, K., UytdeHaag, F., Knell, P. and Morein, B. Comparison of serological responses in cats vaccinated with two different $F e L V$ vaccine preparations. Vet. Rec. 1987, 121, 260

4 Morein, B., Sundquist, B., Höglund, S., Dalsgaard, K. and Osterhaus, A. ISCOM, a novel structure for antigenic presentation of membrane proteins from enveloped viruses. Nature, Lond. 1984, 308, 457

5 Osterhaus, A., Weijer, K., UytdeHaag, F., Jarrett, $O$. and Morein, B Serological responses in cats vaccinated with FeLV ISCOM and an inactivated FeLV vaccine. Vaccine 1989, 7, 137

6 Essex, M., Sliski, A., Cotter, S.M., Jakowski, R.M. and Hardy, W.D. Jr. Immunosurveillance of naturally occurring feline leukemia. Science, N.Y $1975,190,790$

7 Russell, P.H. and Jarrett, O. The specificity of neutralizing antibodies to feline leukemia viruses. Int. J. Cancer 1978, 21, 768

8 Grant, C.K., Essex, M., Gardner, M.B. and Hardy, W.D. Jr. Natural feline leukemia virus infection and the immune response of cats of different ages. Cancer Res. 1980, 40, 823

9 Hanatani, M., Nishifuji, K., Futai, M. and Tsuchiya, T. Solubilization and reconstitution of membrane proteins of Escherichia coliusing alkanoyl- $N$ methylglucamides. J. Biochem. 1984, 95, 1349

10 Hildreth, J.E.K. N-D-Gluco- $N$-methylalkanamide compounds, a new class of non-ionic detergents for membrane biochemistry. Biochem. J. 1982, 207, 363

11 Pinter, A. and Fleissner, E. Structural studies of retroviruses: characterization of oligomeric complexes of murine and feline leukemia virus envelope and core components formed upon cross-linking. J. Virol. 1979, 30, 157

12 Rickard, C.G. Post, J.E., Noronha, F. and Barr, I.M. A transmissible virusinduced lymphocytic leukemia of the cat. J. Natl Cancer Inst. 1969, 42, 987

13 Laemmli, U.K. Cleavage of structural proteins during the assembly of the head of bacteriophage T4. Nature, Lond. 1970, 227,680

14 Towbin, H., Staehelin, T. and Gordin, J. Electrophoretic transfer of proteins from polyacrylamide gels to nitrocellulose sheets: procedure and some applications. Proc. Natl Acad. Sci. USA 1979, 76, 4350

15 Bradford, M.M. A rapid and sensitive method for the quantification of microgram quantities of protein utilizing the principle of protein-dye binding. Analyt. Biochem. 1976, 72, 248

16 Voller, A., Bidwell, D.E., Bartlett, A., Fleck, D.G., Perkins, M. and Oladehin B. J. Clin. Pathol. 29, 150

17 Morein, B. and Simons, K. Subunit vaccines against enveloped viruses: virosomes, micelles and other protein complexes. Vaccine 1985, 3, 83

18 Morein, B., Lövgren, K., Höglund, S, and Sundquist, B. ISCOM-an immunostimulating complex. Immunol. Today 1987, 8, 333

19 Merza, M.S., Linné, T., Höglund, S., Portetelle, D., Burny, A. and Morein, B. Bovine leukemia virus ISCOMs. Biochemical characterization. Vaccine, 7,22

20 Krantz, M.J., Strand, M. and August, J.T. Biochemical and immunological characterization of the major envelope glycoprotein $\mathrm{gp} 69 / 71$ and degradation fragments from Rauscher leukemia virus. J. Virol. 1977, 22, 804

21 Henderson, L.E., Sowder, R., Copeland, T.D., Smythers, G. and Oroszlan, S Quantitative separation of murine leukemia viral proteins by reversedphase high-pressure liquid chromatography reveals newly described gag and env cleavage products. J. Virol. 1984, 52, 492

22 Neil, J.C., Onions, D.E. and Jarrett, O. Polypeptides of feline leukaemia virus: identification of $p 15(E)$ and $p 12(E)$. J. Gen. Virol. 1980, 50, 455 